\title{
Clinical Characteristics of Patients with Subacute Thyroiditis in a Tertiary Hospital
}

\author{
Gulsah Elbuken ${ }^{1, *}$, Ozge Tasgin-Yildirim², Ismail Yildiz ${ }^{1}$, Sayid Shafi Zuhur ${ }^{1}$ \\ ${ }^{1}$ Namik Kemal University, Faculty of Medicine, Department of Endocrinology and Metabolism, Tekirdag, Turkey \\ ${ }^{2}$ Namik Kemal University, Faculty of Medicine, Department of Internal Medicine, Tekirdag, Turkey
}

\begin{abstract}
Introduction: Subacute granulomatous thyroiditis or subacute thyroiditis (ST) is characterized by neck pain or neck tenderness and physical examination usually shows diffuse enlargement and tenderness of the thyroid gland. Its etiology often involves a viral infection and ST manifestations occur during the recovery phase of this infection. In this study, we conducted a retrospective data review of 24 patients diagnosed with ST who were followed at our clinic. Patients and Results: Twenty-four patients (18 females, 6 males) with a mean age ( \pm SD) of $41 \pm 10$ years (min-max: $33-71)$ were followed. There was no significant age difference between males and females. Laboratory findings were as follows: mean sT4 value $2.7 \pm 1.5 \mathrm{ng} / \mathrm{dL}$, sT3 $5.5 \pm 3.3 \mathrm{pg} / \mathrm{ml}$, TSH $0.2 \pm 0.4 \mathrm{mlU} / \mathrm{mL}$, erythrocyte sedimentation rate (ESR) $82 \pm 27 \mathrm{~mm} / \mathrm{h}$, C-reactive protein (CRP) $56.4 \pm 36.5 \mathrm{mg} / \mathrm{L}$, average leukocyte count $8762 \pm 2496 / \mathrm{mm}^{3}$, absolute neutrophil count $5940 \pm 2390 / \mathrm{mm}^{3}$. One patient had elevated anti-thyroid peroxidase (Anti-TPO) and four patients had elevated anti-thyroglobulin (Anti-Tg) antibody levels. The mean time from the onset of an upper respiratory tract infection until ST diagnosis was $39 \pm 28$ days (min-max: 7-90), the mean duration of follow-up was $200 \pm 125$ days (min-max: 30-370) and the mean duration of clinical manifestations of ST was 130 \pm 38 days (min-max: 65-195). Following a ST episode, 19 patients were euthyroid and 3 patients were hypothyroid. The outcome was unknown in 2 patients. Conclusion: ST affects daily life performance adversely due to symptoms of severe neck pain and difficulty swallowing. As can be seen in the case of our patients, the diagnosis of ST is rather difficult unless it is actively sought and on average, it takes 39 days to reach a definite diagnosis. Thus, ST should be considered in the presence of unexplained neck pain with ESR and CRP elevations.
\end{abstract}

Keywords Subacute thyroiditis, Thyroid hormones, C-reactive protein (CRP) elevation, Erythrocyte sedimentation rate (ESR) elevation

\section{Introduction}

Subacute thyroiditis (ST) also known as subacute granulomatous thyroiditis, subacute painful thyroiditis, migratory thyroiditis, non-suppurative thyroiditis, granulomatous thyroiditis, giant cell thyroiditis and de Quervain's thyroiditis characterized by neck pain or neck tenderness and physical examination usually shows diffuse enlargement and tenderness of the thyroid gland [1-3]. ST was first described in 1904 by Fritz de Quervain and named after him who identified giant cells and granulomas in the thyroid gland [4]. It has an incidence of 4.9 per 100.000 and most commonly affects middle-aged individuals and females [5].

Viral infections have usually been implicated in the

* Corresponding author:

gelbuken@nku.edu.tr (Gulsah Elbuken)

Published online at http://journal.sapub.org/ijim

Copyright $\odot 2019$ The Author(s). Published by Scientific \& Academic Publishing

This work is licensed under the Creative Commons Attribution International

License (CC BY). http://creativecommons.org/licenses/by/4.0/ etiology of ST and ST episodes often occur during the convalescence phase of a viral infection. ST has been reported to be associated with infection with several viruses, including mumps, measles, adenovirus, coxsackie and H1N1 [6-9]. Apart from viral agents, ST can be precipitated by cytokines including Interleukin-2, Tumor necrosis factor- $\alpha$ and Interferon- $\alpha$. Most patients report an upper respiratory tract infection prior to ST. Human leukocyte antigen (HLA)-B35 is positive in many patients and HLA-B35 positivity is considered to be associated with an increased risk for development of ST following viral infections [10-12].

Initially, hormone tests reveal thyrotoxicosis as a result of breakdown of thyroid follicles, followed by euthyroid phase and transient hypothyroid phase. Later on, recovery to euthyroid state occurs with resolution of ST manifestations [13]. Hemogram tests indicate leukocytosis and slightly lower $\mathrm{Hb}$ along with elevated erythrocyte sedimentation rate (ESR) and C-reactive protein (CRP). Anti-thyroid peroxidase (Anti-TPO) and anti-thyroglobulin (Anti-Tg) antibodies are usually negative. Thyroglobulin level is often high and it is not recommended to be checked in routine 
practice [13-15]. While thyroid ultrasound (USG) examination is not performed on a routine basis, increased thyroid size, irregular thyroid margins and heterogeneous parenchyma are observed on imaging [16]. Decreased iodine uptake by the thyroid gland is detected [12]. Although fine-needle aspiration (FNA) is not required for the diagnosis, typical FNA findings include degenerated thyroid follicles rich in neutrophils, lymphocytes, histiocytes and multinucleated granulomatous giant cells and destructed follicular cells as well as fibrosis and deposits of colloid [17].

The diagnosis of ST is made on the basis of clinical findings supported by laboratory tests. For treatment, acetylsalicyclic acid or non-steroidal anti-inflammatory drugs (NSAIDs) are used to reduce inflammation, ameliorate pain and provide symptom relief and beta-blockers such as propronolol may be given in order to reduce the effects of increased circulating thyroid hormones in the peripheral blood including tachycardia. In severe cases, steroids may be used as add-on therapy for a period of 4 to 6 weeks to reduce discomfort, symptoms and neck pain $[18,19]$.

In this study, we conducted a retrospective data review of 24 patients diagnosed with ST who were followed at our clinic, in a period of 4 years.

\section{Patients and Results}

Twenty-four patients (18 females, 6 males) with a mean age of $41 \pm 10$ years (min-max: 33-71) were followed. The mean age was $43.2 \pm 9.0$ years for females and $44.5 \pm 13.5$ years for males. There was no significant age difference between males and females.

Laboratory findings (mean \pm values) were as follows: free thyroxine (fT4): $2.7 \pm 1.5 \mathrm{ng} / \mathrm{dL}$, free triiodothyronine (fT3): $5.5 \pm 3.3 \mathrm{pg} / \mathrm{ml}$, thyroid stimulating hormone: (TSH) $0.2 \pm 0.4$ $\mathrm{mlU} / \mathrm{mL}$, ESR: $82 \pm 27 \mathrm{~mm} / \mathrm{h}$, CRP: $56.4 \pm 36.5 \mathrm{mg} / \mathrm{L}$, total leukocyte count: $8762 \pm 2496 / \mathrm{mm}^{3}$, absolute neutrophil count: $5940 \pm 2390 / \mathrm{mm}^{3}$, Anti-TPO: $14.4 \pm 185 \mathrm{IU} / \mathrm{mL}$, and Anti-Tg: $77.9 \pm 175 \mathrm{IU} / \mathrm{mL}$. One patient had elevated Anti-TPO and four patients had elevated Anti-Tg levels. Further laboratory investigations during follow-up showed a mean fT4 value of $1.3 \pm 0.7 \mathrm{ng} / \mathrm{dL}$, fT3 of $2.5 \pm 1.0 \mathrm{pg} / \mathrm{ml}$ and TSH of $2.3 \pm 2.4 \mathrm{mlU} / \mathrm{mL}$ (Table 1).

The mean time from the onset of an upper respiratory tract infection until ST diagnosis was $39 \pm 28$ days (min-max: 7-90), the mean duration of follow-up after ST diagnosis was $200 \pm 125$ days (min-max: 30-370) and the mean duration of clinical manifestations of ST was $130 \pm 38$ days (min-max: 65-195) (Table 1).

Table 1. Demographic and clinical characteristics and laboratory data of study patients

\begin{tabular}{|c|c|c|c|c|c|c|}
\hline Parameter & Mean & $\begin{array}{c}\text { Standard deviation } \\
\text { (SD) }\end{array}$ & Min & Max & $\begin{array}{c}\text { Reference } \\
\text { range }\end{array}$ & Unit \\
\hline $\begin{array}{c}\text { Age, y (n=24) } \\
\text { Females (n=18) } \\
\text { Males (n=6) }\end{array}$ & 41 & 10 & 33 & 71 & & \\
\cline { 2 - 7 } & 43.2 & 9.0 & 33 & 66 & & \\
\hline fT4 & 2.7 & 13.5 & 34 & 71 & & \\
\hline fT3 & 5.5 & 1.5 & 1.1 & 7.8 & $0.8-1.9$ & $\mathrm{ng} / \mathrm{dL}$ \\
\hline TSH & 0.2 & 3.3 & 1.8 & 16.5 & $1.6-5.3$ & $\mathrm{pg} / \mathrm{ml}$ \\
\hline Second fT4 result & 1.3 & 0.4 & 0.01 & 1.3 & $0.4-4$ & $\mathrm{mlU} / \mathrm{mL}$ \\
\hline Second fT3 result & 2.5 & 0.7 & 0.6 & 3.4 & $0.8-1.9$ & $\mathrm{ng} / \mathrm{dL}$ \\
\hline Second TSH result & 2.3 & 1.0 & 1.3 & 5.0 & $1.6-5.3$ & $\mathrm{pg} / \mathrm{ml}$ \\
\hline ESR & 82 & 2.4 & 0.2 & 8.5 & $0.4-4$ & $\mathrm{mlU} / \mathrm{mL}$ \\
\hline CRP & 56.4 & 27 & 12 & 116 & $0-20$ & $\mathrm{~mm} / \mathrm{h}$ \\
\hline Leukocyte count & 8762 & 2496 & 4700 & 15200 & $4400-1000$ & $/ \mathrm{mm}{ }^{3}$ \\
\hline Neutrophil count & 5940 & 2390 & 2000 & 13000 & $1500-7000$ & $/ \mathrm{mm}{ }^{3}$ \\
\hline Anti-TPO & 14.4 & 18.5 & 7.4 & 47.9 & $0-35$ & $\mathrm{IU} / \mathrm{mL}$ \\
\hline Anti-Tg & 77.9 & 175.2 & 14.0 & 681.0 & $0-40$ & $\mathrm{IU} / \mathrm{mL}$ \\
\hline Time from URTI to ST & 39 & 28 & 7 & 90 & & $\mathrm{days}$ \\
\hline diagnosis & 130 & 125 & 30 & 370 & & $\mathrm{days}$ \\
\hline Duration of ST follow-up & 200 & 38 & 65 & 195 & & $\mathrm{days}$ \\
\hline $\begin{array}{c}\text { Duration of ST } \\
\text { manifestations }\end{array}$ & 30.2 & 11.6 & 15 & 60 & & $\mathrm{days}$ \\
\hline Duration of steroid use & & 5.9 & 145.6 & $0-5$ & $\mathrm{mg} / \mathrm{L}$ \\
\hline
\end{tabular}

Abbreviations: n: number of the subjects, min: minimum, max: maximum, fT4: free levothyroxine, fT3: free triiodothyronine, TSH: thyroid stimulating hormone, ESR: erythrocyte sedimentation rate, CRP: C-reactive protein, Anti-TPO: Anti-Thyroid Peroxidase antibody, Anti-Tg: Anti-Thyroglobulin antibody, URTI: Upper Respiratory Tract Infection, ST: Subacute Thyroiditis 
Regarding the type of admission, 18 patients were referred to us with a preliminary diagnosis of ST and 6 patients admitted individually. Nearly all $(\mathrm{n}=22)$ patients had unexplained neck pain and/or painful swallowing. Two patients did not have neck pain at the time of admission due to previous use of NSAIDs. Clear information on the body temperatures could not be obtained from the patients.

Thyroid US examination showed the presence nodules in 6 patients and absence of nodules in 18 patients. Lymphadenomegaly was detected in five patients on neck US imaging. Among 24 patients, iodine uptake was examined only in 4 patients (Table 2).

Before admission to our clinic, 5 patients were given antithyroid medications because of thyrotoxic thyroid hormone tests. Steroids were administered in a total of 19 patients and only NSAIDs were used in 5 patients during follow-up. Steroids administered included prednisolone in 14 patients and methylprednisolone in 5 patients. The mean duration of steroid use was 30.2 days (Table 2).

Following a ST episode, 19 patients were euthyroid and 3 patients were hypothyroid. The outcome was unknown in 2 patients (Table 2).

Table 2. Presenting, imaging and clinical follow-up characteristics of study patients

\begin{tabular}{|c|c|c|c|}
\hline Type of & $\begin{array}{c}\text { Referral from an } \\
\text { external facility }\end{array}$ & \multicolumn{2}{|c|}{ Individual admission } \\
\hline & $\mathrm{n}=18$ & \multicolumn{2}{|c|}{$n=6$} \\
\hline & Present & \multicolumn{2}{|c|}{ Absent } \\
\hline $\begin{array}{c}\text { painful } \\
\text { swallowing }\end{array}$ & $\mathrm{n}=22$ & \multicolumn{2}{|c|}{$\mathrm{n}=2$} \\
\hline Neck USG & $\begin{array}{c}\text { Lymph node } \\
\text { present }\end{array}$ & \multicolumn{2}{|c|}{ Lymph node absent } \\
\hline & $\mathrm{n}=5$ & \multicolumn{2}{|c|}{$\mathrm{n}=19$} \\
\hline Thyroid USG & $\begin{array}{c}\text { Thyroid nodule } \\
\text { present }\end{array}$ & \multicolumn{2}{|c|}{ Thyroid nodule absent } \\
\hline & $n=6$ & \multicolumn{2}{|c|}{$\mathrm{n}=18$} \\
\hline Jodine untake & Examined & \multicolumn{2}{|c|}{ Not examined } \\
\hline Toume uptake & $\mathrm{n}=4$ & \multicolumn{2}{|c|}{$\mathrm{n}=20$} \\
\hline Previous use & Yes & \multicolumn{2}{|c|}{ No } \\
\hline $\begin{array}{c}\text { of antithyroid } \\
\text { medications }\end{array}$ & $\mathrm{n}=5$ & \multicolumn{2}{|c|}{$\mathrm{n}=19$} \\
\hline Previous & Yes & \multicolumn{2}{|c|}{ No } \\
\hline antibiotic use & $\mathrm{n}=6$ & \multicolumn{2}{|c|}{$\mathrm{n}=18$} \\
\hline & Yes & \multicolumn{2}{|c|}{ No } \\
\hline $\begin{array}{l}\text { Previous } \\
\text { steroid use }\end{array}$ & $\mathrm{n}=5$ & \multicolumn{2}{|c|}{$\mathrm{n}=19$} \\
\hline & $\mathrm{n}=19$ & \multicolumn{2}{|c|}{$\mathrm{n}=5$} \\
\hline Steroids & Prednisolone & \multicolumn{2}{|c|}{ Methylprednisolone } \\
\hline administered & $n=14$ & \multicolumn{2}{|c|}{$\mathrm{n}=5$} \\
\hline \multirow[t]{2}{*}{$\begin{array}{l}\text { In long-term } \\
\text { follow-up }\end{array}$} & Euthyroid & Hypothyroid & $\begin{array}{c}\text { Outcome } \\
\text { Not } \\
\text { known } \\
\end{array}$ \\
\hline & $\mathrm{n}=19$ & $\mathrm{n}=3$ & $\mathrm{n}=2$ \\
\hline
\end{tabular}

Abbreviations: n: number of the subjects, USG: ultrasonography

\section{Discussion}

ST manifests with inflammation of the thyroid gland often following a viral infection and adversely affects the daily life performance of the patient due to several symptoms such as severe pain and difficulty swallowing. As with our patient series, ST usually affects middle-aged persons and predominantly females $[4,5]$. The diagnosis of ST is based on clinical findings. Excluding 2 patients without neck pain due to previous use of NSAID therapy, 22 patients reported severe neck symptoms. In fact, these patients presented to our clinic in an effort to obtain relief from their persistent symptoms. Neck-related symptoms included pain radiating to the face, unexplained neck pain, tenderness when gentle pressure is applied to the thyroid gland, discomfort in the anterior part of the neck, and painful or difficulty swallowing. Although most patients reported a history of an upper respiratory tract infection (URTI) prior to ST at presentation, they did not describe high-grade fever. Thus, patient history of elevated body temperature could not be confirmed. ST diagnosis was made and treatment initiated on the basis of physical examination findings, elevated ESR and CRP and persistent anterior neck symptoms in the absence of high-grade fever.

Consistent with the literature, 24 patients of whom the majority were females with a mean age of 40 years presented to our clinic in a period of 4 years [4]. Detection of reduced thyroid iodine uptake is another finding that supports the diagnosis and was used in only 4 of our patients to confirm the diagnosis.

In general, patients with ST test negative for thyroid autoantibodies. In our sample, elevation of thyroid autoantibodies was observed in only 5 patients. The etiopathogenesis of ST involves destruction of thyroid follicles as a result of thyroiditis and subsequent release of thyroglobulin and thyroid hormones. Destruction of thyroid follicles may produce a thyrotoxicosis episode due to release of thyroid hormones into the peripheral blood. This does not represent a true clinical picture of hyperthyroidism and a euthyroid state may occur following clearance of thyroid hormones from the peripheral blood and even hypothyroidism may be observed until thyroid follicles have been completely healed to resume hormone synthesis [5, 13]. Accordingly, a substantial portion of our patients remained in euthyroid state over the long-term follow-up. Final hormonal status was unknown for 2 patients who were lost to follow-up. In the literature, permanent hypothyroidism was reported in 14.3 to $25 \%$ of patients after ST and about $1 / 8$ of our sample ( 3 out of 24 patients; $12.5 \%$ ) had permanent hypothyroidism [3, 4, 13]. However, there were 2 other patients with unknown outcome and the shortest follow-up duration was 30 days. Thus, an exact number of patients with permanent hypothyroidism cannot be provided. Exclusion of 3 patients with a follow-up duration of less than 60 days resulted in a permanent hypothyroidism percentage of $3 / 21$ (14.3\%) compatible with Alfadda AA et al. [3] and this is not an exact figure either due to 2 patients with unknown 
outcome. Additionally, thyroid autoantibodies were positive in 3 patients with hypothyroidism. Unfortunately, thyroid hormone values prior to ST were missing in these patients. Both ST and autoimmune thyroiditis are two conditions that may cause hypothyroidism. Moreover, there is one study in literature that reported unremitting neck pain in patients with Hashimoto's tyroiditis. In that study, Hashimoto's thyroiditis was diagnosed based on fine needle aspiration biopsy (FNAB) and surgical pathology of the thyroid gland [20]. In contrast, none of our patients underwent FNAB. Therefore, Hashimoto's thyroiditis with neck pain was excluded as a differential diagnosis on the basis of ESR and CRP elevations. Consequently, it was not possible to exactly determine which of these two conditions led to hypothyroidism in these 3 patients.

This suggests that ST may have caused hypothyroidism but autoimmune chronic thyroiditis might also be the cause (This wording (in green) may be deleted and wording in red may be included in the Discussion section).

Often ST is a self-limiting disease; inflammation subsides and then completely resolves after a while with clinical manifestations assuming a milder course followed by eventual recovery. In order to properly manage this process, ST diagnosis should be initially considered and subsequently confirmed and adequate symptomatic therapy instituted as needed. The mean time from the onset of an upper respiratory tract infection until the diagnosis was 39 days in our patients. Among the patients, 18 were referred by other physicians from external facilities with a preliminary ST diagnosis and $6(25 \%)$ patients with unresolved complaints presented on their own. Prior to admission to our clinic, 6 patients had been given antibiotics unnecessarily due to misdiagnoses including acute pharyngitis or tonsillitis and 5 patients had received antithyroid medications inappropriately without identification of the root cause of thyrotoxicosis. This suggests that there is a need to better educate physicians on the clinical and laboratory findings of ST and to increase physician awareness of ST $[15,21]$. The symptoms of ST persisted for a mean duration of 130 days in our patients and the total average duration of follow-up for ST at our outpatient clinic was 200 days and mean duration of steroid therapy was 30.2 days in patients receiving steroids. Taking into account these long periods of time, it is reasonable to consider that quality of life and daily work performance of ST patients would be affected significantly. Therefore, management of ST should include reduction of symptoms such as neck pain, difficulty swallowing, fever, malaise and tachycardia as much as possible and maximal protection of the individual patients against work loss.

\section{Conclusions}

As can be seen in the case of our patients, the diagnosis of ST is rather difficult unless it is actively sought. Thus, ST should be considered in the presence of unexplained neck pain with ESR and CRP elevations.

\section{ACKNOWLEDGEMENTS}

This manuscprit sent to be presented as a scientific poster in $41^{\text {st }}$ Turkish Congress of Endocrinology and Metabolism in $27^{\text {th }}$ April- $1^{\text {st }}$ May 2019, Antalya, Turkey.

\section{REFERENCES}

[1] Lazarus JH. Silent thyroiditis and subacute thyroiditis. In: The Thyroid: A Fundamental and Clinical Text, 7th Ed, Braverman LE, Utiger RD (Eds), Lippincott Williams \& Wilkins, Philadelphia 1996. p.577.

[2] Pearce EN, Farwell AP, Braverman LE. Thyroiditis. The New England Journal of Medicine. 2003; 348(26): 2646-55.

[3] Alfadda AA, Sallam RM, Elawad GE, Aldhukair H, Alyahya MM.Subacute thyroiditis: clinical presentation and long term outcome. Int J Endocrinol. 2014;2014:794943.

[4] Fatourechi V, Aniszewski JP, Fatourechi GZ, et al. Clinical features and out come of subacute thyroiditis in an incidence cohort: Olmsted County, Minnesota, study. J Clin Endocrinol Metab 2003; 88: 2100.

[5] Engkakul P, Mahachoklertwattana P, Poomthavorn P. Eponym: de Quervain thyroiditis. Eur J Pediatr. 2011; 170(4): 427-31.

[6] Desailloud R, Hober D. Viruses and thyroiditis: an update. Virol J 2009; 6:5.

[7] Volpé R, Row VV, Ezrin C. Circulating viral and thyroid antibodies in subacute thyroiditis. J Clin Endocrinol Metab 1967; 27(9): 1275-84.

[8] Cunha BA, Berbari N. Subacutethyroiditis (de Quervain's) due toinfluenza A: presenting as fever of unknown origin (FUO). Heart Lung. 2013; 42(1): 77-8.

[9] Michas G, Alevetsovitis G, Andrikou I, Tsimiklis S, Vryonis E. De Quervain thyroiditis in the course of H1N1 influenza infection. Hippokratia 2014; 18(1): 86-7.

[10] Li H, Zhang X, Gao L, Min J, Zhang Y, Zhang R, Yang Y.TNF-alpha is upregulated in subacute thyroiditis and stimulates expression of miR-155-5p in thyroid follicle cells. Discov Med. 2018; 26(142): 67-77.

[11] Ohsako N, Tamai H, Sudo T, et al. Clinical characteristics of subacute thyroiditis classified according to human leukocyte antigen typing. J Clin Endocrinol Metab 1995; 80: 3653.

[12] Khan SH, Mahajan A, Laway BA, Rasool R, Rather TA.Technetium-99m Thyroid Scintigraphy and Human Leukocyte Antigen- B35 in Sub-AcuteThyroiditis. Indian J Nucl Med. 2018; 33(4): 306-11.

[13] Nishihara E, Ohye H, Amino N, et al. Clinical characteristics of 852 patients with subacute thyroiditis before treatment. Intern Med 2008; 47:725.

[14] Pearce EN, Bogazzi F, Martino E, et al. The prevalence of elevated serum C-reactive protein levels in inflammatory and noninflammatory thyroid disease. Thyroid 2003; 13:643.

[15] Raj R, Yada S, Jacob A, Unnikrishnan D, Ghali W. Fever of 
Unknown Origin as a Sole Presentation of Subacute Thyroiditis in an Elderly Patient: A Case Report with Literature Review. Case Rep Endocrinol. 2018; 25: 5041724.

[16] Park SY, Kim EK, Kim MJ, et al. Ultrasonographic characteristics of subacute granulomatous thyroiditis. Korean J Radiol 2006; 7:229.

[17] Lamichaney R, Sherpa M, Das D, Bhutia CT, Laishram S. Fine-Needle Aspiration of De Quervain's Thyroiditis (Subacute Granulomatous Thyroiditis): A Cytological Review of 20 Cases. J Clin Diagn Res. 2017; 11(8): EC09-EC11.

[18] Sato J, Uchida T, Komiya K, Goto H, Takeno K, Suzuki R, Honda A, Himuro M, Watada H. Comparison of the therapeutic effects of prednisolone and nonsteroidal anti-inflammatory drugs in patients with subacute thyroiditis. Endocrine. 2017; 55(1): 209-14.

[19] Arao T, Okada Y, Torimoto K, et al. Prednisolone Dosing Regimen for Treatment of Subacute Thyroiditis. J UOEH. 2015; 37(2): 103-10.

[20] Kon YC, DeGroot LJ. Painful Hashimoto's thyroiditis as an indication forthyroidectomy: clinical characteristics and outcome in seven patients J Clin Endocrinol Metab. 2003; 88(6): 2667.

[21] Das S. Subacute thyroiditis: An uncommoncause of fever of unknown origin. Indian J Endocrinol Metab. 2012; (Suppl 2): S340-1. 